\title{
Livestock, Colonialism, and Commodity Frontiers in the U.S. Southwest
}

Andrew Curley

Keywords: Navajo, livestock, settler-colonialism, commodity frontier, decolonization

Abstract: Commodity frontiers are a useful way to think about the expansion and rearticulation of capitalist modes of production across the globe. A weakness of this approach is to miss deeper histories of colonialism and domination at the sites of the metaphorical frontier. This commentary discusses Diné relationships with sheep to think through how livestock often contains older relationships that transcend colonial limitations.

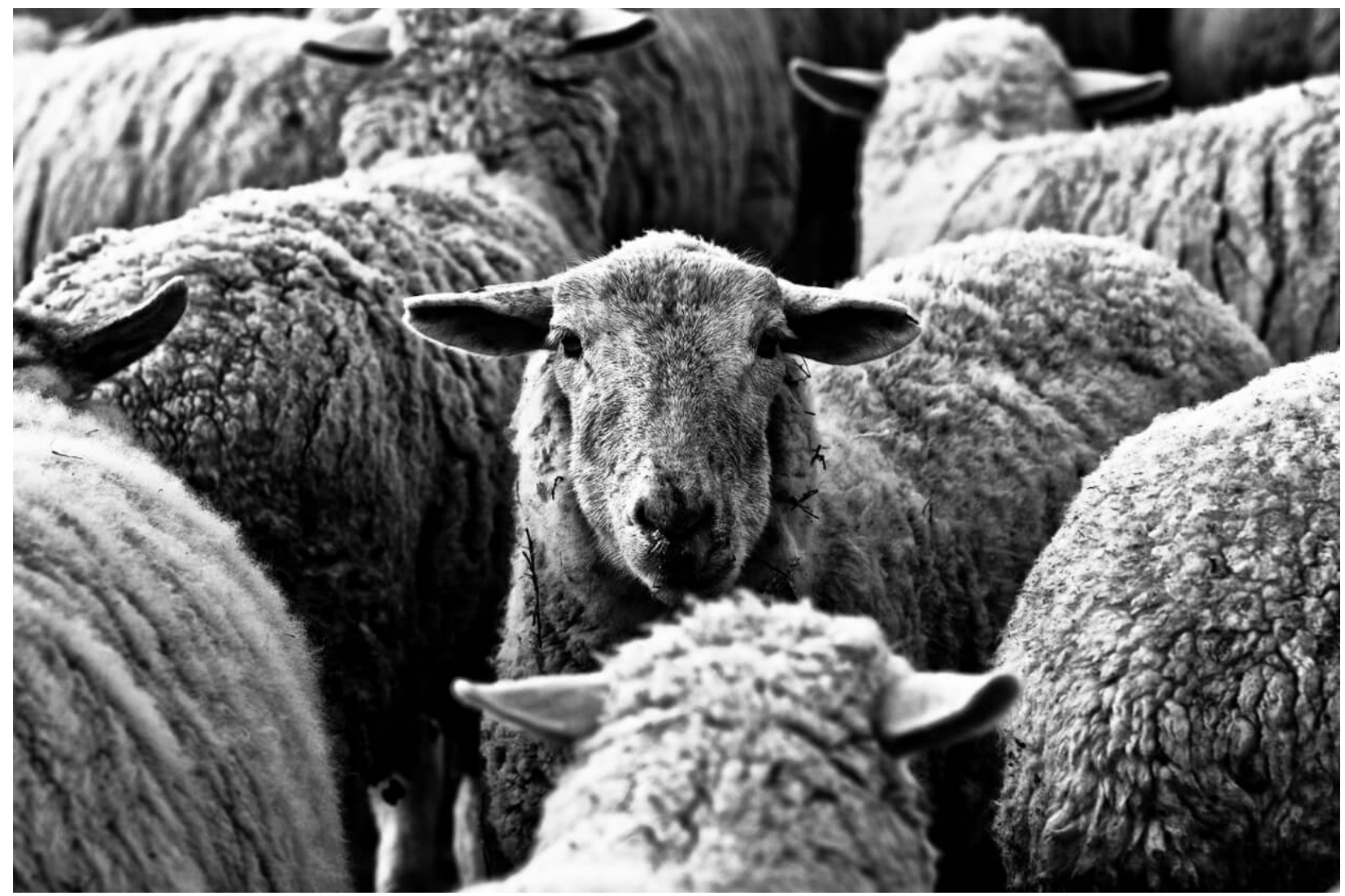

Photo: Donovan Shortey, www.navajophotography.com, 2012.

$\mathrm{T}$ he commodity frontiers concept euphemizes a kind of violence on people and the land. Frontiers are a violent, world-making process. They refer to the destruction of past worlds, brought into the control of new colonial logics. Much commodity frontiers scholarship largely takes its prompt from Jason Moore, who imagined frontiers as a metaphor - as a new space of capital incorporation of people, places, and their things (Moore 2000).

In this article, I want to push back against the metaphor - to say frontiers are literal sites of struggle. 
For the Diné people in the southwestern United States, frontier-making was a violent process. It involved targeted racial killings, harassment, theft, and reprisals. The frontier was initiated as an abstract state making process - lines on a map with purposeful exclusion of people who were already there. Frontier making was a disciplinary project involving the use of the United States military, coordinated attacks against civilians and their infrastructures, and forced internment. In short, frontiers were plans of land dispossession realized through the barrel of a gun.

Focusing too intently (and abstractly) on the commodity and not the places where commodities are produced can elide questions of settler expansion, colonialism, and domination. Let's consider one site of colonial struggle as experienced between the history of two nonhuman "commodities," cattle and sheep.

Although Spanish brought sheep to the southwest (Weisiger 2011), the sheep didn't like their colonial masters and moved to live with the Diné, becoming an integral part of life. Diné and sheep built a reciprocal relationship. Dibe, the Diné word for sheep, were dependent on humans for survival. They needed guidance to know where to eat, drink, and sleep. On their own, without the protection of humans, Dibe had little chance against the area's natural predators, wolves, bears, and coyotes.

Diné people brought Dibe into their lives and expanded territory to fulfil their needs. It was a human-animal space making process distinct from the Spanish land grant system that dominated notions of land tenure in the Rio Grande Valley following the conquest of New Mexico.

Cattle, on the other hand, unmade and remade Indigenous geographies. Cattle destroyed worlds, decimated species such as the bison, and led to range wars that left Indigenous peoples on poorly resourced reservations.
$\mathrm{T}$ oday's commodity frontiers analogize the colonial-capital drive of westward expansion. Once the lands of the west were conquered, they were turned into cattle range - feeding an expanding diet of meat consumption in settler communities through expansion of rail, technology, and markets (Cronon 1992, Specht 2019). Diné range land was circumscribed, and reservation boundaries strictly enforced (Kelley and Francis 2019).

While range land expanded in the southwest and rivers were dammed, desertification was blamed on Diné sheepherders. New Deal policies of soil restoration, a scientific approach to range management, targeted Diné sheep. During the 1940s, soil crop scientists imposed grazing restrictions and fixed boundaries on family's grazing lands. Historian Richard White suggested livestock reduction was responsible for the Navajo Nation's (colonial name for the Diné people) economic dependency today (White 1983).

With the imposition of U.S. style grazing restrictions, came a change in how Diné people understood the land and Dibe. Dibe weren't a companion on the landscape, but an object for consumption, abstracted to the idea of carrying capacity. The Commissioner of Indian Affairs imposed grazing districts on the tribe in 1943, translating carrying capacity into sheep units.

Range technicians estimate how many sheep the range can support. The sheep, as an abstract consumer of range, becomes an equation against the consuming capabilities of other range animals, namely horses and cattle. The ratio of sheep to horses is 1 to 5 while cattle is 1 to 4 . This means 1 horse is worth five sheep. If the land has an estimated carrying capacity of 10 sheep, this means the land can alternatively support up to 2 horses ${ }^{1}$.

Today cattle is a dominant industry in Arizona. It accounts for $73 \%$ of total land use and $98 \%$ of Arizona's agricultural land. In

2011 , cattle sales were $\$ 800$ million $^{2}$. In the Navajo Nation, sheep are still dominant. In 2012 USDA counted almost 51,000 heads of

1 https://www.ecfr.gov/current/title-25/chapter-I/subchapter-H/part-167.

$\underline{2 \text { https://economics.arizona.edu/contribution-beef-industry-arizona-economy. }}$ 


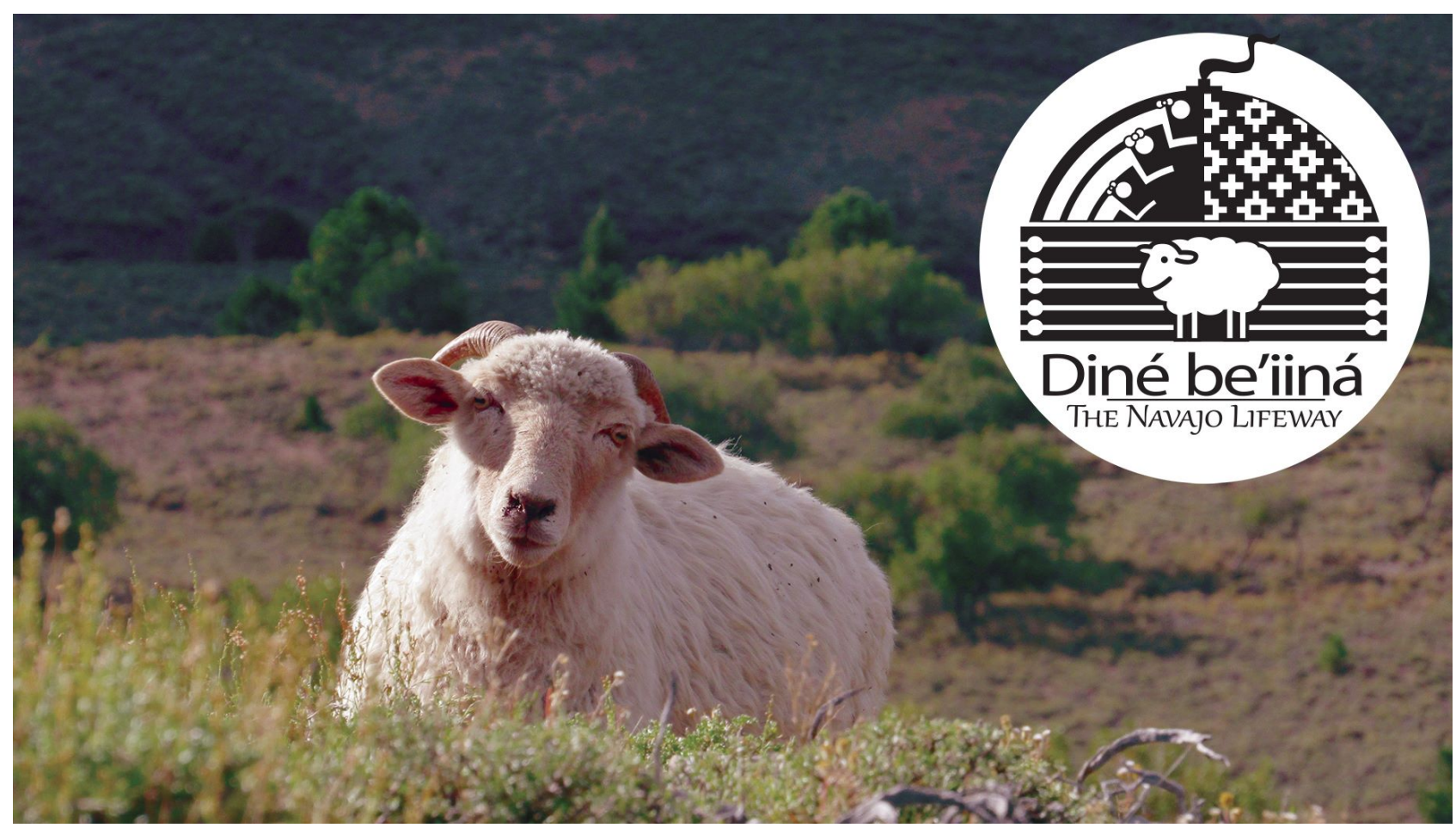

Image from the Diné Be'iná, “Sheep is Life” Facebook page. Diné Be’iiná logo was created by Harry McCabe. Imaged used with permission.

cattle in the Navajo Nation, but with 171,107 sheep $^{3}$. The development of cattle and sheep in southwestern rangelands follow longer standing patterns of understandings of the land between two different kinds of living, colonizer and colonized.

For the Diné, the sheep remain central to subsistent life on the Colorado Plateau. It is a central area of decolonial struggle. In a 2016 report to the Navajo Times, then 17-year-old Vanessa Martinez (Diné), told reporter Arlyssa Becenti, "I have this concept of decolonizing myself, and this was a way to start. This was a way to do it and everything else will follow through ... this makes you want to get sheep and do all that."4 Today Martinez is a board member on the organization, "Sheep is life". The purpose of the organization is to "promote sustainable livelihood through the Navajo way of life." 5 Although the organization is small and their website isn't flashy, the idea central to their work - sheep is life - is a challenge to the settler-colonial ontology of land, commodity, dispossession. It signals a fundamentally different way of interacting with the natural world beyond the notion of frontiers and domination.

With force, colonizers killed bison, stole Indigenous lands, and put up barbed-wire fences around their vast ranches. Indigenous nations were forced to conform to this understanding of land, animals, and markets but not completely. Even with land restrictions and grazing units, Diné traditional lifeways challenge commodity frontiers.

\section{References}

Cronon, W. (1992). Nature's Metropolis : Chicago and the Great West. New York: W.W. Norton. Kelley, K. \& H. Francis. (2019). A Diné History of Navajoland. University of Arizona Press.

3 https://www.nass.usda.gov/Statistics by State/Regional_Office/Mountain/includes/more features/
Navajo Chapterhouse Summary/Navajo-Nation-Summary-by-Agency.pdf

4 https://navajotimes.com/ae/culture/decolonizing-myself/.

\section{5 https://navajolifeway.org/navajo-sheep/.}


Moore, J. W. (2000) Sugar and the Expansion of the Early Modern World-Economy: Commodity Frontiers, Ecological Transformation, and Industrialization. Review (Fernand Braudel Center), 23, 409-433.

Specht, J. (2019). Red Meat Republic: A Hoof-To-Table History of How Beef Changed America. Princeton, NJ: Princeton University Press.

Weisiger, M. (2011). Dreaming of sheep in Navajo Country. Seattle, WA: University of Washington Press. White, R. (1983). The roots of dependency: subsistence, environment, and social change among the Choctaws, Pawnees, and Navajos. Lincoln, NE: University of Nebraska Press.

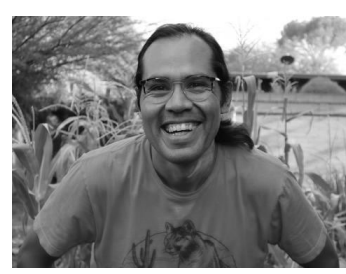

Andrew Curley is Assistant Professor in the School of Geography, Development \& Environment at the University of Arizona. His research focuses on the everyday incorporation of Indigenous nations into colonial economies. He publishes ethnographic research on how Indigenous communities understand coal, energy, land, water, infrastructure, and development in an era of energy transition and climate change.

\section{Correspondence:}

Andrew Curley, apcurley@arizona.edu.

\section{Cite this article:}

Curley, A. (2021). "Livestock, Colonialism, and Commodity Frontiers in the U.S. Southwest." Commodity Frontiers 3: 37-40. doi: 10.18174/cf.2021a18162.

Commodity Frontiers is an open-access journal edited by the CFI Editorial Board, Mindi Schneider, senior editor. Read it online at Commodity Frontiers, or our website, commodityfrontiers.com.

This work is licensed under a Creative Commons Attribution-NonCommercial 4.0 International License 